\title{
A música do ponto de vista do nativo: um ensaio bibliográfico
}

\author{
Eduardo Henrik Aubert ${ }^{1}$ \\ Doutorando em História - Groupe d'Anthropologie Historique \\ de l'Occident Medieval/École des Hautes Études en Sciences Sociales \\ (GAHOM-EHESS)
}

\begin{abstract}
RESUMO: O presente artigo busca caracterizar as diferentes posições que a musicologia comparada, na primeira metade do século XX, e a etnomusicologia, sua herdeira na segunda metade do século, desenvolveram a respeito do pensamento sobre a música nas culturas que estudaram. Se, em um primeiro momento, a percepção da (in)existência desse pensamento esteve marcada pela oposição à teoria musical ocidental, o reconhecimento da diversidade de seu conteúdo e, depois, de sua forma foi gradualmente conquistando a disciplina. A tal ponto que hoje se pode perguntar, dialeticamente, se, para além da diversidade do pensamento sobre a música, não há uma unidade do pensamento musical como modalidade cognitiva característica da espécie.
\end{abstract}

PALAVRAS-CHAVE: musicologia comparada, etnomusicologia, teoria musical, pensamento sobre a música, pensamento musical.

Rompendo com os estudos tradicionais de história da música e de teoria musical, delineia-se, no século XIX, o campo da ciência da música, ou da musicologia. O grande sentido dessa ruptura é a criação de um objeto: a música do passado. Ao falar sobre Karl Franz Friedrich Chrysander (1826-1901), que cunhou a expressão musikalische Wissenschaft 
Eduardo Henrik Aubert. A música do ponto de vista do nativo...

("ciência musical", depois Musikwissenschaft, "ciência da música", ou "musicologia"), Rafael Bastos caracterizou o processo da seguinte maneira: "O que esse handelista notório assim intentava era uma ruptura com a tônica daqueles estudos em seu tempo, profundamente colada a uma estética do presente. [...] A criação, portanto, do termo musicologia, na segunda metade do século XIX, parece apontar para um movimento na direção da própria invenção do objeto música do passado" (Bastos, 1995, pp. 40ss). A criação da música do passado, alteridade com relação à música do presente, será seguida, no final do século, da invenção de mais um "outro": a música não ocidental, também abarcada no campo em expansão da musicologia, sob a denominação de "musicologia comparada", termo cunhado por Guido Adler em 1885 (Adler, 1885, p. 14). ${ }^{2}$ Essa dupla alteridade da música ocidental do presente (com relação à música do passado e à música não ocidental) foi construída com base em algumas premissas muito fortes, como a distinção entre música de arte e música funcional, a presença ou a ausência da polifonia, entre outras. Uma delas, que assume papel especialmente marcante na caracterização das disciplinas, é a posição atribuída à teoria musical em cada uma dessas "músicas". Vista como um dos elementos definidores da música ocidental do presente, a teoria musical inexistiria nas culturas não ocidentais e estaria presente na música ocidental do passado apenas de forma rudimentar e primitiva, sofrendo uma evolução gradual em direção ao presente - para um exemplo dessa narrativa, conferir Riemann (1974). Como disse Steven Feld, "a teoria musical era aceita como uma realização especial do Ocidente que permitia a 'nós' analisar a 'eles'” (Feld, 1990, p. 63).

Neste artigo, buscaremos caracterizar as posiçôes que a musicologia comparada e sua herdeira a partir da década de 50 do século $\mathrm{XX}$, a etnomusicologia, desenvolveram a respeito do papel da "teoria musical" (a expressão não é neutra e, como se verá, as alterações de perspectiva 
implicam sempre uma redefinição do objeto - "conceito musical”, "pensamento sobre a música", "pensamento musical" e assim por diante) nos sistemas musicais e culturais que estudaram, acompanhando aquelas que parecem ser as formulações mais importantes e suas principais transformações. O problema correlato da posição da teoria musical na música ocidental anterior ao século XIX não será abordado neste texto, com vistas a um desenvolvimento futuro.

\section{Os primitivos não têm teoria da música!}

A época de ouro da musicologia comparada é identificada à chamada Escola de Musicologia Comparada de Berlim, no começo do século XX, e a suas duas grandes personagens, Carl Stumpf (1841-1936) e Erich Moritz von Hornbostel (1877-1935) (Christensen, 1991, pp. 201-9). Hornbostel, especialmente, foi uma figura crucial, tanto por seu trabalho pessoal, constituído por inúmeras publicações que integravam musicologia, psicologia e antropologia, como pelos discípulos, diretos ou indiretos (Kolinski, Bose, Herzog), que a ele se associaram e que seriam os formadores da primeira geração de etnomusicólogos norte-americanos dos meados do século XX. Por essa razão, é interessante passar em revista algumas das afirmaçóes de Hornbostel a respeito do pensamento dos nativos sobre a música.

Ainda que, em alguns de seus primeiros trabalhos, Hornbostel tenha sugerido que algum dia os julgamentos estéticos expressos em línguas não européias poderiam vir a interessar os musicólogos comparativos, os métodos que tinha à disposição não permitiam "tirar conclusões confiáveis sobre a concepção do próprio cantor" (Hornbostel, 1909, p. 782). Adotando, duas décadas depois, uma posição mais cética, Hornbostel marcava, em relação à música negra africana, "a amplitude 
Eduardo Henrik Aubert. A música do ponto de vista do nativo...

estreita da consciência" que havia impedido um grupo humano de organizar e utilizar um conjunto de recursos musicais (id., 1928, p. 38). Do mesmo modo, ao tocar no problema das afinações instrumentais que George Herzog, um de seus discípulos não formais, associaria a teorias musicais nativas, ainda que muito parciais, como veremos mais adiante -, Hornbostel afirmou mais de uma vez que "mal se poderia falar de um 'sistema'” (apud Blum, 1991, p. 28).

A exclusão da "teoria musical" do campo da musicologia comparada é plenamente compreensível no conjunto desses pressupostos. Afinal, a noção de teoria era afim àquela de sistema, que, no esquema proposto por Adler em 1885, tinha seu lugar no subcampo da musicologia sistemática, domínio de estudo da música ocidental do presente. A musicologia comparada trabalhava, assim, nos quadros das divisões disciplinares - e de seus pressupostos operantes - tal como esses haviam sido delimitados pela musicologia alemã do final do século XIX.

Curt Sachs (1881-1959), historiador da arte e da música, cujo nome é freqüentemente associado ao de Hornbostel devido ao importante trabalho que escreveram em parceria sobre organologia (Hornbostel \& Sachs, 1914), também subscreve a esse paradigma, afirmando que, na música "primitiva", "a imitação e a expressão involuntária da emoção precedem toda a formação consciente do som" (Sachs, 1937, p. 175). Esse modelo de compreensão da música "primitiva" estava articulado, como seu negativo, a uma percepção evolutiva, por parte da musicologia, da relação entre teoria e produto musical. De acordo com Riemann, por exemplo, passar-se-ia de uma época em que a teoria era "agente do progresso [do ponto de vista do produto]" para outra, no século XVI, em que ela estaria subordinada à prática, ao menos do ponto de vista da polifonia (Riemann, 1974, p. xxi). Se, no caso da música ocidental, há, portanto, uma transformação evolutiva na ordem de encadeamento dos 
dois elementos, teoria e prática, no das culturas não ocidentais, a teoria estaria pura e simplesmente ausente.

Outro nome importante a ser investigado nesse momento é o de Franz Boas (1858-1942), que manteve correspondência com os musicólogos comparados da Escola de Berlim, especialmente com Hornbostel, e que orientou alguns dos nomes que viriam a constituir a primeira geração da etnomusicologia americana, dentre eles, George Herzog, o discípulo informal de Hornbostel a que já aludimos, orientador de Bruno Nettl, e Melville Jean Herskovits, professor de Alan P. Merriam. Boas, fundador da antropologia cultural americana e crítico combativo do evolucionismo, interessou-se bastante pela música não ocidental. Em seu trabalho mais importante no que tange ao estudo da música, Primitive Art (1927), Boas começa por enunciar seus princípios de investigação. O primeiro deles é a "igualdade fundamental dos processos mentais em todas as raças e em todas as formas culturais atuais” (Boas, 1951, p. 1): "não há algo como a 'mente primitiva', um modo de pensar 'mágico' ou pré-lógico', mas cada indivíduo na sociedade 'primitiva' é um homem, uma mulher, uma criança do mesmo tipo, da mesma maneira de pensar, sentir e agir que o homem, a mulher ou a criança em nossa própria sociedade" (id., p. 2). A diferença do "civilizado" seria de ordem histórica - e o segundo princípio da investigação de Boas é a "consideração de todo fenômeno cultural como o resultado de acontecimentos históricos" (id., p. 1). Segundo Boas, "nossa vantagem com relação aos povos primitivos é a de um maior conhecimento do mundo objetivo, conseguido pelo trabalho de muitas gerações" (id., p. 4). É a um menor conhecimento do "mundo objetivo" que devemos, então, associar a seguinte afirmação de Boas, no capítulo dedicado à literatura, música e dança: "Não adentrarei mais nesse assunto intricado, pois ainda não se achou um método que nos permita dizer de forma definitiva o que as 
Eduardo Henrik Aubert. A música do ponto de vista do nativo...

pessoas querem cantar quando entre elas não há uma teoria da música, como ela existe entre nós ou entre os povos civilizados da Ásia, e quando elas não têm instrumentos construídos com exatidão" (id., p. 342). Ainda que o homem "primitivo" não se distinga mentalmente do "civilizado", a tradição passou a este um conjunto de idéias baseadas em séculos de experimentos, diferentemente do que se deu com o homem "primitivo" (id., 1939, pp. 201ss). É daí que decorre a existência de um corpo de conhecimentos do mundo objetivo melhor do que as "classificaçôes inconscientes" dos homens "primitivos". Não se trata de capacidade ou incapacidade, mas de imposição da tradição, tanto em um caso como em outro. O resultado, entretanto, é o de que as idéias dos "primitivos" sobre o mundo - e sobre a música - são "inteiramente inconscientes" (id., p. 198), o que é exatamente o contrário da existência de uma teoria da música, expressão que pressupóe necessariamente um elevado nível de consciência. Temos aqui, portanto, no campo antropológico, para além do já aludido musicológico, uma fundamentação para a não existência de uma teoria musical não ocidental (exceção feita aos povos "civilizados" da Ásia).

George Herzog parece ter sido um dos primeiros antropólogosmusicólogos - a palavra "etno-musicologia", hifenizada até 1955, só surge em 1950 (Bastos, 1995, pp. 16-7) - a acenar para a possibilidade de se falar em teorias musicais com relação às culturas musicais não ocidentais - querendo, assim, aludir à complexidade do pensamento não ocidental sobre a música, segundo a concepção corrente de "teoria". Em um estudo sobre os tambores entre os Jabo na África Ocidental, Herzog escreveu:

Ainda que essas teorias nativas sejam parciais, [...] elas demonstram como a terminologia e a teoria técnica podem bem se desenvolver onde existe um objeto ou um instrumento no qual um sistema de outro modo abstra- 
Revista de Antropologia, São Paulo, USP, 2007, v. 50 No 1.

to possa ser observado em operação visível; o desenvolvimento da teoria musical e de um sistema de escalas também está relacionado a observações dos instrumentos musicais, não da voz cantada ou de fenômenos acústicos no abstrato. (Herzog, 1945, p. 232)

É interessante notar a correlação aqui estabelecida entre instrumento e teoria musical, associação já sugerida no trecho que citamos da obra Primitive Art, de Boas. A correlação está fundamentada, muito provavelmente, nos trabalhos da musicologia comparada voltados à comparação de escalas musicais via medição dos tubos de instrumentos de sopro, notadamente das flautas de Pã, e pode remeter, direta ou indiretamente, aos trabalhos de Helmholtz dos meados do século XIX. ${ }^{3}$ Mas, mesmo aqui, trata-se de uma nota marginal e que qualifica as "teorias nativas" de "parciais". Ainda se está longe da definição de um objeto de estudo. De fato, onze anos depois, um orientando de Herzog, o etnomusicólogo Bruno Nettl, que depois viria a se tornar um dos maiores expoentes da disciplina, afirmava, sem reticências ou reservas, que "na música primitiva uma escala não existe na mente dos músicos nativos, e então o musicólogo precisa deduzi-la das melodias" (Nettl, 1956, p. 45). Esse era, afinal, o senso comum da disciplina.

É curioso, mas bastante compreensível, dados os pressupostos disciplinares da musicologia comparada, que a declaração mais direta no sentido do estudo de "teorias musicais nativas" venha de Marcel Mauss, um antropólogo que jamais se dedicou ao estudo da música, ainda que eventualmente em sua proposta de análise de "fatos sociais totais" fizesse menção a ela. Durante conferências realizadas entre 1926 e 1939, Mauss chegou mesmo a fazer um uso explícito da noção de "teoria": "Nós encontramos nas artes musicais dois elementos: um elemento sensorial correspondente às noçôes de ritmo, de equilíbrio, de contrastes $\mathrm{e}$ de harmonia, e um elemento ideal, um elemento de theoria: [...] a mais 
Eduardo Henrik Aubert. A música do ponto de vista do nativo...

simples das artes musicais comporta um elemento de imaginação e de criação" (Mauss, 1926, p. 82). Mauss referiu-se também - testemunho seguro de suas leituras dos musicólogos comparados - às flautas de Pã como possíveis instigadoras do desenvolvimento de uma "teoria nativa" da música: "Existe uma teoria da música em todo lugar em que existe a flauta de Pã. Distingue-se o comprimento dos tubos e aprecia-se a altura absoluta de seus sons, os intervalos" (Mauss, 1926, p. 85). Entretanto, não é daqui que surgirá uma proposta de análise do pensamento não ocidental sobre a música (ainda que, em certa medida, os trabalhos de Lévi-Strauss sobre mito e música possam ser considerados um tipo muito específico de encaminhamento para esse interesse), mas sim da etnomusicologia americana, na linhagem de Boas. Referimo-nos à obra de Alan P. Merriam, aluno de Herskovits, que examinaremos na seqüência.

\section{Eles têm conceitos musicais, mas teoria da música...}

Alan P. Merriam (1923-1980) foi possivelmente a personagem mais influente na constituição da etnomusicologia americana no século XX, especialmente em razão de seu livro The Anthropology of Music, de 1964, um vasto ensaio em forma de manual que tem servido até hoje como fonte de propostas e discussões. Merriam tinha como propósito escrever um livro que preenchesse uma lacuna, pois, em um campo que, segundo ele, se formava na confluência da musicologia e da antropologia, muito menos atenção havia sido dada à antropologia: "o fato é que as técnicas musicológicas foram aplicadas a um número surpreendente de músicas do mundo, com resultados significativos, ainda que certamente não definitivos; as questôes relativas ao comportamento humano e à ideação em conjunto com a música mal foram formuladas" (Merriam, 1980, p. viii). Desse ponto de vista, as idéias relativas à música, os "con- 
ceitos musicais", como os chamou, pareciam fundamentais. Mas, como se vê, a noção de "conceitos" surge explicitamente vinculada ao aporte antropológico dessa confluência que definiria a etnomusicologia, e não do lado musicológico, em que a noção de teoria musical permaneceu fortemente impregnada.

Para compreender essa noção de "conceitos musicais" na obra de Merriam, é preciso examinar alguns pontos de sua contribuição à disciplina. Em primeiro lugar, deve-se atentar para o quadro geral de sua proposta, o "modelo Merriam", como poderíamos chamá-lo. No referido The Anthropology of Music, Merriam busca formular um campo de estudos como interesse específico no seio da etnomusicologia, uma espécie de subcampo, denominado exatamente "antropologia da música". Esse subcampo seria dedicado a um estudo em três níveis: "a conceituação sobre a música, o comportamento em relação à música e o som musical propriamente dito" (id., p. 32). Essa tríade é fundamental, pois envolve um direcionamento específico, o conceito produzindo o comportamento (divisível em três níveis, físico, social e verbal), e este produzindo o som. Trata-se de um modelo de níveis superpostos, em um influxo unidirecional. Delineia-se aqui um encadeamento causal, e no gatilho do processo está precisamente o conceito. Daí que Charles Keil tenha classificado a proposta de Merriam como idealista (Keil, 1979, p. 6). Cabe notar, entretanto, que Anthony Seeger se opôs à "redução" do pensamento multifacetado de Merriam a esquemas rígidos e simples (Seeger, 1987a), e é fato que o "modelo Merriam", como veremos, jamais apareceu de forma tão esquemática na prática etnomusicológica de Merriam.

Um segundo elemento para o qual gostaríamos de chamar atenção é a existência, para Merriam, de uma distinção entre "conceitos" e "teoria musical" propriamente dita: "Nossos interesses aqui não estão voltados para as distinções que as pessoas possam fazer entre terças maiores e 
Eduardo Henrik Aubert. A música do ponto de vista do nativo...

menores, por exemplo, mas antes para qual é a natureza da música, como ela se encaixa na sociedade como parte dos fenômenos existentes da vida, e como ela é organizada conceitualmente pelo povo que a usa e a organiza" (id., p. 63). Trata-se de proposta que distingue, de um lado, os elementos tradicionais da teoria musical ocidental e, de outro, um campo, igualmente excludente, dos "conceitos musicais", entendidos, sobretudo, como uma espécie de metafísica da música. Trata-se, como se vê, de uma categorização a priori muito fundamentada em uma construção ocidental, segundo a qual "idéia" é tudo aquilo que não é "teoria" musical - e vice-versa -, construção que pressupõe uma divisão entre discurso técnico (sobre escalas, tons, acordes, intervalos etc.) e metafísico ou funcional (sobre a natureza da música, seus efeitos e suas funções, entre outros), que é muito própria da cultura musical do Ocidente, em que o primeiro tipo de discurso é o apanágio de um grupo de especialistas.

Conforme veremos, essa distinção de duas esferas de idealização, estrutural na obra de Merriam, foi na seqüência criticada por diversos autores, na medida em que, ao invés de questionar os pressupostos devidos aos quais a musicologia comparada negara a existência de uma "teoria musical" não ocidental, domínio dito "técnico" e exclusivo do Ocidente, ela a reforçava. Aqui fica bastante claro que Merriam está de fato inserido naquele "paradigma dilemático" que dominou longamente a idéia que se fazia da etnomusicologia e de fato direcionou, em grande parte, o seu desenvolvimento: de um lado, a proposta que enfatizava a musicologia - e, aqui, já que o discurso sobre a música é entendido fundamentalmente como linguagem técnica de intervalos, escalas e modos, a "teoria musical" não encontrava lugar, o objeto de estudo reduzindose ao produto musical "bruto" -, de outro, a proposta de Merriam, que enfatizava a antropologia - e, aqui, como a ênfase era na "música na cultura” (id., p. 6), essa era atrelada a um conjunto de conceitos metafísicos, atinentes à generalidade da cultura, e não à especificidade da 
música advogada pelos protagonistas da vertente mais musicológica da disciplina.

Na prática etnomusicológica, a proposta de Merriam redundou, mais que em uma efetiva articulação explicativa, em uma sobreposição temática da esfera dos conceitos musicais com as outras duas esferas de seu modelo (o comportamento e o som). Isso fica bastante claro na monografia escrita por Merriam três anos depois (1967), The Ethnomusicology of the Flathead Indians. O livro está dividido em duas partes: "A etnografia da música Flathead" e "Canções e análise". A primeira inicia com as idéias e envereda pelos comportamentos, e a segunda trata do produto musical. Repete-se aqui a contraposição entre duas modalidades ideacionais, uma técnica (relativa à especificidade da música), não necessariamente presente nas culturas nativas, a outra amplamente difundida (atinente à generalidade da cultura):

Todas as pessoas, não importa em que cultura, devem ser capazes de localizar a música firmemente no contexto da totalidade de suas crenças, experiências e atividades, pois, sem esses laços, a música não pode existir. Isso significa que tem de haver um corpo de teoria ligado a qualquer sistema de música - não necessariamente uma teoria da estrutura do som musical, apesar de ela também poder estar presente, mas antes uma teoria do que a música é, e como ela é coordenada com o ambiente total, tanto natural como cultural, em que o homem se movimenta. (Merriam, 1967, p. 3)

Aqui a associação entre verbalização e conceituação - noções centrais no livro de 1964 - é enfatizada, entretanto, de modo que o postulado estritamente causal de The Anthropology of Music não assuma uma proeminência discursiva. De fato, para Merriam, "assim como eles verbalizam relativamente pouco sobre os critérios para um bom cantor, e, quando este é o caso, apenas em um plano não técnico, os Flathead 
Eduardo Henrik Aubert. A música do ponto de vista do nativo...

também não conceituam sua música de forma a permitir discussões técnicas de estrutura formal" (id., p. 41).

Como veremos em breve, a obra de Merriam foi alvo de diversas críticas, e vários elementos de seu "modelo" foram reavaliados ao longo do tempo. Por ora, vamos abrir um parêntese e identificar outro estudioso, John Blacking (1928-1990), contemporâneo de Merriam, e que, durante seu doutoramento, se correspondeu com este, vendo seu próprio trabalho em grande parte como uma "antropologia da música". Segundo Blacking em uma entrevista de 1989, "apenas em 1964, o ano em que saiu o The Anthropology of Music de Merriam, eu vi alguma diferença: muito embora eu admirasse o livro, e muito embora eu ainda apoiasse praticamente tudo o que Merriam escreveu nele, eu sentia que não havia no livro atenção suficiente ao lado musical" (Blacking \& Howard, 1991, p. 60). Em seu livro sobre as canções das crianças venda, de 1967 , mesmo ano do estudo de Merriam sobre os Flathead, Blacking, abrindo o prefácio de seu livro com uma referência a Merriam, tomava uma posição sutil mas crucialmente distinta: "O importante livro de Alan Merriam, The Anthropology of Music, enfatiza a necessidade de se estudar a música na cultura. Decorre daí que, se a música for considerada como ação humana, o som da música não pode mais ser analisado independentemente, mas deve ser estudado como som na cultura" (Blacking, 1995a, p. 5). Para Blacking, não se trata de trabalhar na sobreposição do antropológico e do musicológico, como na etnografia de Merriam, mas de entender a imbricação desses domínios para além do "paradigma dilemático".

Em sua obra, Blacking dedicou algumas páginas a "Algumas definiçôes e conceitos básicos da música venda" (id., pp. 16-19). Nelas fica bastante evidente que se está diante de um modelo que encara os "conceitos" musicais de forma bem diferente da de Merriam. Em primeiro lugar, "definiçóes" e "conceitos" aparecem juntos, sem distinção 
Revista de Antropologia, São Paulo, USP, 2007, v. 50 No 1.

causal - precisamente a correlação entre verbalização e conceito, que, em The Anthropology of Music, se relaciona como produto e produtor respectivamente. Em segundo, não existe privilégio a priori de uma terminologia não técnica por oposição a uma terminologia técnica, ou dois níveis de ideação. Afinal, Blacking está interessado em incorporar em seu estudo o som musical e a análise musical das peças. Em terceiro, forma e função, ou situação, estão intimamente relacionados: "A música é essencialmente uma atividade social” (id., p. 17). Em quarto, há uma inversão, por assim dizer, do direcionamento de Merriam - conceito $\rightarrow$ (comportamento) $\rightarrow$ som. Para Blacking, em certa medida (pois não generaliza a afirmação), o som gera o conceito: "Porque sua música consiste basicamente em repetições de padrōes básicos, eles não têm um conceito de pausas na performance" (ibid.). Em quinto, Blacking não sobrepõe conceitos nativos a conceitos ocidentais, mas relaciona uns com os outros, verificando correspondências mais que reconstruindo sistemas em sua inteireza. É importante atentar para essas especificidades da obra de Blacking e para sua precoce contraposição a Merriam, pois, tratando-se de obra bem menos lida que a de Merriam, ela não suscitou tantos comentários diretos. Porém, ela levanta questōes e sugere elementos de um modelo que será muito importante a partir da década de 1980, como se verá mais adiante. Retomaremos a contribuição de Blacking para a etnomusicologia no último item deste texto.

\section{Os nativos têm teorias complexas, como mostram suas elaboradas taxonomias musicais...}

Inovadora e ousada, a obra de Merriam calou fundo o campo então em constituição da etnomusicologia norte-americana, como testemunha a recepção, extremamente crítica em muitos pontos, de The Anthropology 
Eduardo Henrik Aubert. A música do ponto de vista do nativo...

of Music e de The Ethnomusicology of the Flathead Indians. É o caso de uma resenha escrita por William Powers ao livro sobre os Flathead, em 1970, em que a questão dos "conceitos musicais" foi especialmente destacada (Powers, 1970). Sem negar a importância dos "conceitos musicais", Powers opõe-se, contudo, à exclusão do pensamento técnico sobre a música do horizonte de Merriam e, nessa crítica, detém-se especificamente sobre a questão da correlação entre conceituação e verbalização tal como vista por Merriam:

Ficamos curiosos para saber se a "inabilidade" para verbalizar sobre a música não pode ser resultado da maneira como as questões musicais foram formuladas aos informantes. Além do mais, se o pesquisador não fala a língua nativa, ele não está em condições de ter certeza se uma população ágrafa é ou não capaz de verbalizar sobre a música em um sentido técnico [...]. Eu concordaria com Merriam em que a maior parte dos índios não verbalizam sobre sua música em inglês nem se articulam bem sobre o canto quando respondem a questōes que não podem ser respondidas em seus próprios contextos culturais. A isso eu acrescentaria que os intérpretes também têm dificuldade em se expressar tanto em sua própria língua como em inglês sobre muitas facetas de sua cultura tradicional, dependendo grandemente de seu nível de aculturação. Mas eu não posso concordar com que os Flathead, ou quaisquer outros grupos de índios que são capazes de formular extensas taxonomias de fenômenos naturais, não sejam capazes de verbalizar satisfatoriamente sobre sua música de acordo com suas necessidades sociais. (id., p. 72)

Critica-se aqui a distinção postulada por Merriam entre conceituação e verbalização, que marginaliza, de certo modo, a mediação do pensamento pela língua. O movimento em que a etnomusicologia se engajará na década de 1970 é exatamente o oposto, o de colocar essa 
Revista de Antropologia, São Paulo, USP, 2007, v. 50 No 1.

mediação no centro de seus interesses. As taxonomias e a importância dada ao uso da língua nativa na pesquisa etnográfica enfatizam, na resenha de Powers, a centralidade da expressão verbal como porta de entrada para a compreensão de uma cultura e dão testemunho da ligação do autor, especialista dos índios Lakota, com a emergente antropologia cognitiva. Esse campo resulta da associação da antropologia com a lingüística, e é preocupado, de acordo com um de seus primeiros e mais influentes manuais, com a organização mental do mundo pelos nativos tal qual ela pode ser percebida pela linguagem e objetivada em modelos taxonômicos (Tyler, 1969). Uma conseqüência importante dessa abordagem é que, preocupando-se com a sistematização do pensamento na língua, ela acaba permitindo que eventualmente a própria noção de teoria musical, que está associada a certa sistematicidade e a uma organização objetiva das categorias, entre finalmente no campo da etnomusicologia.

A centralidade da mediação da língua está associada a uma mudança de perspectiva mais global, que transparece no seguinte trecho da resenha de Powers: "quando se trata de analisar tais fenômenos como a verbalização da música e conceitos de estrutura formal e estética, há uma maior necessidade para os etnomusicólogos se 'de-culturarem' da orientação ocidental e seguirem a dica dos proponentes da etnociência, isto é, 'pensarem como índios'” (Powers, 1970, p. 70). Aqui se delineiam os termos do debate êmico/ético, que dominaria a cena antropológica nas próximas décadas. A primeira posição defende que se adote um "ponto de vista nativo", e a segunda que se assuma o ponto de vista externo, ocidental (Headland, Pike \& Harris, 1990). A defesa generalizada da adoção de um ponto de vista êmico pela etnomusicologia de vertente preponderantemente antropológica seria decisiva no estabelecimento de um campo de estudos de "teorias musicais nativas", como esses estudos passaram a se denominar a partir de então. Nesse sentido, a recepção do 
Eduardo Henrik Aubert. A música do ponto de vista do nativo...

trabalho de Merriam defronta-se imediatamente com as dificuldades levantadas por transformações de fundo na antropologia.

Um importante trabalho que participa desse mesmo movimento global da disciplina é o Glossary of Hausa Music and Its Social Contexts, de David W. Ames e Anthony V. King, de 1971, e é compreensível que Jones veja no livro uma contribuição não apenas a etnomusicólogos, mas também a lingüistas e lexicógrafos, já que a importância da mediação da língua se torna aqui a coluna vertebral do trabalho (Jones, 1973). O objetivo dos autores não é, entretanto, o de montar um simples dicionário, como se poderia imaginar pelo título. Eles pretendem "fazer deste mais do que um glossário técnico de instrumentos musicais e produção sonora; de fato, ele acabou por se tornar um tipo de etnografia abreviada da vida musical, em que o mesmo peso é dado ao contexto sociocultural da performance musical” (Ames \& King, 1971, p. vii). O glossário está dividido em cinco seções: (I) "Instrumentos e suas partes"; (II) "Artistas profissionais"; (III) "Patronos"; (IV) "Ocasiōes"; (V) "Performance musical". A perspectiva é a de, por meio da língua hausa, descortinar as categorias nativas de pensamento sobre a música, isto é, partir da língua para chegar ao pensamento - o que é, no mínimo, uma inversão metodológica do encadeamento ontológico proposto por Merriam. Trata-se, ademais, como marcou Nettl, de um quadro essencialmente êmico do nicho que a música ocupa nessa cultura, ainda que certas classificações sejam importadas "de fora" - caso da classificação dos instrumentos musicais, que segue a sistemática de Hornbostel e Sachs (Nettl, 1983, pp. 143-4).

Um dos etnomusicólogos mais destacados na defesa do estudo das "teorias musicais nativas" foi Hugo Zemp, que trabalhou primeiramente com os Dan, na Costa do Marfim, e depois com os 'Are'are, na Melanésia. Logo em seu primeiro livro, Musique dan: la musique dans la pensée et la vie sociale d'une société africaine, de 1971, os "conceitos musicais" 
Revista de Antropologia, São Paulo, USP, 2007, v. 50 No 1.

assumem papel preponderante. ${ }^{4}$ Nesse trabalho, dividido em três partes - "Instrumentos de música", "Concepções e verbalizaçôes" e "Contexto social" -, a segunda parte insiste, já em seu título, na correlação entre conceituação e verbalização. Ao explicar essa parte do livro na introdução, Zemp a define da seguinte maneira: "nós estudaremos as concepções relativas à música: qual é - segundo os Dan - a natureza da música, como ela está integrada na cultura como uma parte dos fenômenos da vida, como ela é conceituada" (Zemp, 1971, p. 13). Como se vê, tudo aquilo que Merriam definira como "conceito musical" por oposição à "teoria", no sentido de pensamento técnico, encontra aqui um lugar. Na seqüência, naturalmente, Zemp cita o livro de Merriam, The Anthropology of Music, no momento em que o antropólogo chama a atenção para a distinção entre música e ruído (cf. Merriam, 1980, p. 63), e aqui se delineiam as diferenças. Diz Zemp:

Mas não basta que o antropólogo pergunte em sua língua aos membros de uma sociedade como eles concebem essa distinção. É necessário, primeiramente, determinar se termos que cobrem essas noções européias de "música" e de "ruído" existem e, sobretudo, se elas possuem o mesmo campo semântico que os termos da língua utilizada pelo pesquisador, o que é pouco provável para línguas não européias. É por isso que nós abrimos, na nossa obra, a parte consagrada às concepções com um inventário do vocabulário dan de interesse musical. O perigo de compreender mal as informaçôes ou de as reinterpretar segundo uma concepção eurocêntrica da música é particularmente grande nesse domínio. Se nós nos preocupamos sempre em colocar os diferentes termos em seu contexto lingüístico e em traduzir as expressões dan literalmente, citando o texto original, é para ficarmos o mais próximos possível do pensamento dan, mesmo se nos arriscamos a fatigar demasiadamente o leitor, que não é nem dan nem semanticista. (Zemp, 1971, p. 13) 
Eduardo Henrik Aubert. A música do ponto de vista do nativo...

Vê-se aqui como é mais uma vez a centralidade da mediação da língua que se impõe, postulado metodológico que se desdobra em perspectiva filosófica, segundo a qual o pesquisador tem de se desvestir de suas categorias (música e ruído, por exemplo) para entender a outra cultura em sua alteridade radical. É preciso, em outros termos, que o pesquisador se dispa de seu ponto de vista e busque assumir o ponto de vista do outro.

Ao longo da década de 1970, Zemp se deterá sobre seu distanciamento com relação a Merriam e o precisará. Em artigo de 1978, "Are'Are Classification of Musical Types and Instruments", Zemp insistirá na arbitrariedade da separação entre música e ruído tal qual formulada por Merriam: "Ao estudar conceitos de música, o primeiro imperativo é usar a língua nativa para a investigação" (id., 1978, p. 59). E, naturalmente, à centralidade da mediação da língua, associa-se a perspectiva êmica: "Esses traços não são empregados artificialmente a partir de fora, mas correspondem a conceitos inerentes ao pensamento 'are'are, que são expressos freqüentemente no vocabulário dos músicos" (id., p. 61). O nexo entre língua e pensamento é muito estreito, e negligenciálo seria incorrer certamente em etnocentrismo, fantasma que esses pesquisadores buscam, acima de tudo, espantar. No ano seguinte (1979), Zemp publica outro artigo sobre os 'Are'are na Ethnomusicology, "Aspects of 'Are'Are Musical Theory". Aqui, Zemp acaba por extrair da população toda uma complexa "teoria musical", assim nomeada, aliás, no título do artigo. No final do texto, Zemp dedica algumas páginas à crítica da postura de Merriam, pondo-se a tratar das relações entre a verbalização e os conceitos e de como extrair esses elementos do trabalho de campo. É importante ressaltar que, aqui, não se trata mais de "conceitos musicais", como em Merriam, mas de uma "teoria musical", estruturada, complexa e verbalizada. Conclui Zemp: "Oceania, África [...] isso significa que talvez a teoria musical não seja um privilégio das 'músicas 
artísticas' das assim chamadas 'civilizações elevadas' da Europa e da Ásia, como muitos musicólogos (com ou sem o prefixo etno-) ainda defendem hoje? O título deste artigo deixa clara a nossa posição" (id., p. 34). A sistematicidade metodológica, com suas taxonomias complexas, está casada aqui com o postulado de uma sistematicidade do pensamento dos nativos sobre a música, que acaba por ser vista como o fundamento ontológico dessa metodologia. Afinal, constroem-se taxonomias lingüísticas porque o pensamento nativo é correspondentemente sistemático, ou o pensamento nativo é visto como sistemático, no sentido taxonômico, em função da metodologia adotada?

Esses trabalhos, com uma ênfase formalista importante, associada também à voga do estruturalismo na década de 1970 - Zemp reconhece explicitamente, em seu trabalho sobre a música dan, a importância dos seminários de Lévi-Strauss a que assistiu (id., 1971, p. 15) -, são todos de forte inspiração antropológica e pouco se ocupam do lado musicológico do "paradigma dilemático". Porém, mesmo esse espectro da pesquisa etnomusicológica sofreu, na década de 1970, o impacto da preocupação com as "teorias musicais nativas". É o caso dos trabalhos de Gerhard Kubik reunidos nos dois volumes de seu Theory of African Music. Nos diversos artigos, Kubik está preocupado em extrair uma teoria musical de seus informantes que dê conta da estrutura musical das peças. Ele buscou freqüentemente a verbalização dessas categorias, mas não as encontrou quase nunca no que respeita à "estrutura musical", que lhe interessava estudar. Kubik chega a supor: "Regras prescritivas para a composição devem ter existido no passado. Elas devem ter sido verbalizadas por alguns dos antigos compositores e seguidas pela maioria como normas geralmente aceitas de comportamento composicional entre as famílias de músicos responsáveis pela música de corte" (Kubik, 1994, v. 1, p. 266). Freqüentemente, Kubik deduziu os "conceitos" da música africana dos atos, da educação, da performance, e não das pala- 
Eduardo Henrik Aubert. A música do ponto de vista do nativo...

vras, mas - e é aqui que se revela o impacto da corrente das "teorias musicais nativas" mesmo no campo mais musicológico da disciplina ele buscou encontrá-las: "Os termos luganda, não importa quão descritivos das partes individuais, oferecem pouca indicação quanto a suas características estruturais. Portanto, eu esboçarei abaixo as principais características das duas partes básicas na música amadinda, baseado em minhas próprias observações em campo" (id., v. 1, p. 275). Assim, Kubik é freqüentemente levado a uma abordagem ética, mas sua tentativa repetida, ao longo dos ensaios, de partir das possibilidades êmicas revela muito a respeito do impacto da constituição de um campo de interesse pelas "teorias musicais nativas" na etnomusicologia.

\section{Taxonomia? Mas como os nativos pensam a música?}

O primado lingüístico associado à antropologia cognitiva vai se apagando, ou ao menos virando objeto de polêmica, conforme a década de 1970 vai se aproximando de seu fim. É de 1978 que data um inovador trabalho etnomusicológico, o livro Tiv Song, de Charles Keil, em que estão apontados muitos dos caminhos que a etnomusicologia trilharia na década seguinte. Os cinco capítulos do livro foram escritos entre 1966 e 1973 e mantidos praticamente sem revisão quando da publicação. Isso faz do livro, escrito por um autor que se mostra um leitor ávido do que foi sendo publicado pela etnomusicologia e pela teoria antropológica, um interessante "termômetro" de transformaçôes mais gerais da disciplina. Os primeiros quatro capítulos, segundo o próprio Keil, “exemplificam um estudo idealista [...], aprendido mais diretamente da versão da realidade de Alan Merriam, dos-conceitos-ao-comportamento-aoproduto, e das visōes de Clifford Geertz e David Schneider dos sistemas culturais flutuando simbolicamente acima dos eventos da vida cotidia- 
na” (Keil, 1979, p. 6). Daí que seu primeiro capítulo se dedique - e assim vemos que, seja idealista ou não, o trabalho de Keil não segue exatamente o "modelo" de Merriam, para quem a verbalização é posterior à conceituação - à terminologia tiv, o segundo às narrativas tradicionais em que a música desempenha papel importante, o terceiro à vida de compositores e o quarto à técnica e ao estilo. Já no quinto capítulo, Keil identifica uma tendência de se tornar mais e mais "materialista", "alguém que acredita que os sistemas culturais são organizados, desorganizados e reorganizados por forças socioeconômicas" (id., p. 7). Daí que este último capítulo seja distinto dos demais, ao inserir as canções tiv no mundo social de forma marcada. $\mathrm{Na}$ primeira perspectiva, entendemos o primeiro capítulo de Keil, "A terminologia musical", como um desenvolvimento específico da crítica cognitiva a Merriam mais que como um estudo em perfeita consonância com as propostas do último -, insistindo na importância da língua e da perspectiva êmica. De fato, para Keil, seguindo Janheiz Jahn, "o equivalente de uma estética ou de uma 'ideologia da expressão' está enraizado em uma língua africana” (id., p. 26). E, com efeito, logo em seguida, Keil critica Merriam por sua desatenção para com a terminologia (id., pp. 28-9). A perspectiva êmica é explícita: "a 'música' [notem-se as aspas] tiv deve ser analisada em seus próprios termos" (id., p. 47). O capítulo cinco, de outro lado, abre-se - sempre com a preocupação de desvendar as categorias tiv em um ponto de vista êmico - interessado em apontar para uma "teoria da expressão tiv", buscando "virar de cabeça para baixo a teoria, o método e os modelos etnocêntricos de Lévi-Strauss, substituindo seus quadros, tabelas e paradigmas estáticos, ex cathedra, por uma forma de compreender particularidades dinâmicas em contexto" (id., p. 183). O que Keil busca aqui é entender o significado da canção tiv em contexto como um sistema expressivo que está articulado às situações específicas a que os significados estão associados, não em função de uma gramática musi- 
Eduardo Henrik Aubert. A música do ponto de vista do nativo...

cal que sobrevoa a vida social. Seja ou não bem-sucedido, ${ }^{5}$ Keil aponta, neste último capítulo, para algumas das preocupações que se manifestariam em seguida no estudo das "teorias musicais nativas" - e que, aos poucos, conduziriam à própria reconfiguração do objeto. O grande problema parece ser o de que aquilo que identifica como "idealismo" e "materialismo" surge como posturas antinômicas no interior de seu livro, dificultando a conciliação interna do trabalho. Daí que os demais estudos que aparecem a partir de então, e que manifestam a mesma preocupação social com a compreensão da música do ponto de vista do nativo, não condenem o estruturalismo de Lévi-Strauss, por exemplo, mas busquem combiná-lo com outras referências.

Um estudo escrito logo após o de Keil, mas publicado um pouco antes dele, é $A$ musicológica kamayurá: para uma antropologia da comunicação no Alto-Xingu, de Rafael José de Menezes Bastos, dissertação de mestrado defendida na Universidade de Brasília em 1976 e publicada em forma de livro em 1978. O objeto da dissertação é "o metassistema de cobertura verbal do sistema musical dos índios kamayurá do AltoXingu; metassistema este que inclui, basicamente, classificação e nomenclatura das coisas musicais" (Bastos, 1978, p. 15). Trata-se, declaradamente, de um primeiro passo de uma pesquisa que pretende se desdobrar em doutorado. Na primeira fase da pesquisa, Rafael Bastos tem a intenção de analisar o "falar sobre música", enquanto, no doutorado, pretende tratar do "fazer música". Trata-se de um estudo da música do ponto de vista "verbal-cognitivo", em que o autor é bastante explícito sobre suas referências teóricas: a antropologia cognitiva e o estruturalismo. Em sua introdução teórica, Bastos condena a postura, segundo ele prevalecente,

[...] antinômica, dualista, entre expressão e conteúdo musicais, avalizada não somente, em particular, pela etnomusicologia, mas também pela an- 
Revista de Antropologia, São Paulo, USP, 2007, v. 50 No 1.

tropologia como área abrangente, [que] tem sido elaborada de muitas e diferentes maneiras, segundo, no entanto, três direçōes principais. A primeira delas se contém no estudo da primeira parte do dilema, a segunda, da segunda, a terceira, enfim, tentando a pura e simples justaposição de ambas. (id., p. 38)

No primeiro grupo, os expoentes seriam Mantle Hood e Mieczislav Kolinski, no segundo, Alan Lomax, e, no terceiro, Alan Merriam. E, aqui, realiza-se uma crítica ao trabalho de Merriam sobre os índios Flathead, centrada na divisão do livro em duas partes justapostas, e não integradas. Diz Bastos: "Se bem que o trabalho evidencie o pleno domínio pelo autor, em separado, dos dois objetos de sua análise, a impressão crucial que aqui se leva é a de uma desconcatenação essencial entre os mesmos, desconcatenação esta que acaba, dramaticamente, por deixar claro como Merriam, ao mesmo tempo em que se esforça por superar o dilema, dele simplesmente não consegue fugir, porque primordialmente nele se amarra" (id., pp. 40-1). Mas a crítica se tece em termos distintos daqueles que pudemos acompanhar em Powers ou Zemp, especialmente no que tange à relação com a lingüística, que assumia, como vimos, um papel fundamental nesses autores. Para Bastos,

[...] a língua falada, tomada como modelo por excelência da linguagem, ela estando sustentada nos planos de expressão e de conteúdo, na cognição como forma de conhecimento e, particularmente, no plano de conteúdo, tendo a referência como inclinação básica, a transposição desse modelo para o estudo da música só pôde trazer o aprisionamento desta, notoriamente uma linguagem essencialmente não referencial, onde a cognição só aparece no plano expressivo, o afeto e a psicomotricidade constituindo sua vocação semântica maior. (id., p. 43) 
Eduardo Henrik Aubert. A música do ponto de vista do nativo...

O primado da língua como mediação para o pensamento é posto em causa e, como proposta alternativa, Rafael Bastos sugere uma abordagem do objeto em função da antropologia da comunicação, tal qual preconizada por Dell Hymes. A referência aqui é bastante importante, dada a crítica de Hymes à lingüística (tal qual aquela que inspirara a antropologia cognitiva), em que a língua está dissociada de seu contexto comunicativo. Segundo Hymes, em texto que busca definir as bases de sua "etnografia da comunicação", "a ênfase da abordagem presente é em comunidades organizadas como sistemas de eventos comunicativos" (Hymes, 1974, p. 17). O objeto aqui é social, e, por essa via, Bastos se mostra afinado com a mesma preocupação que guiara Keil no último capítulo de Tiv Song.

Estudando o caso do Alto-Xingu, o trabalho de Rafael Bastos se centrará mais especificamente na noção de ritual como forma de tentar dar conta dessa preocupação com os contextos comunicativos. Apesar de a dissertação se centrar no problema do "falar musical" - mais que no do pensar - e não no do fazer, tem-se aqui uma proposta que objetiva fundamentar uma análise ampla do papel da música nessas sociedades. Nesse panorama, o dilema verbal-conceitual inexiste, ao passo que a dimensão social do "falar sobre música", como parte integrante da comunicação, está acentuada. Sobre este último ponto, diz Rafael Bastos:

Conforme se verá no capítulo III desta tese - basicamente a parte propriamente etnocientífica dela -, o que essa afirmação técnica me permitiu foi o levantamento de um sistema verbal-cognitivo altamente aceitável em termos sociais, isto na medida em que, propiciando ele o discurso lingüístico sobre a música, torna possível a comunicação entre os membros da sociedade kamayurá no que a isso diz respeito - e, para o Kamayurá, a música é tema crucial -, salientando-se aqui o plano da socialização. (Bastos, 1978, p. 48) 
Outra monografia a que se deve chamar atenção é Sound and Sentiment: Birds, Weeping, Poetics, and Song in Kaluli Expression, de Steven Feld, publicada pela primeira vez em 1982, com base na tese de doutoramento defendida na Universidade de Indiana em 1979. A monografia está centrada no estudo dos Kaluli, população que habita a floresta tropical nas terras altas ao sul de Papua Nova-Guiné. O objetivo do autor é realizar um "estudo do som como um sistema cultural, isto é, um sistema de símbolos" (Feld, 1990, p. 3). O estudo de Feld se desenvolveu com base na percepção daquilo que ele chama de um padrão recorrente em modalidades sonoras diversas entre os Kaluli, especificamente o choro, a música vocal e a poética. Para o autor, essas modalidades estariam todas integradas por uma referência comum: "A tese deste trabalho é de que as modalidades expressivas kaluli de choro, poética e música vocal, em sua estrutura musical e textual, são representações espelhadas do círculo simbólico construído pelo mito 'o menino que se tornou um pássaro muni” (id., p. 14). Um estudo puramente ideacional portanto? Feld nomeia diretamente suas principais referências teóricas de forma a sugerir uma resposta negativa: o estruturalismo de LéviStrauss, a descrição densa de Geertz e a antropologia da comunicação de Hymes (ibid.). Para Feld, a importância de integrar essas referências reside no seguinte: "parece-me [...] que é necessário integrar o estudo de como os símbolos são logicamente relacionados [estruturalismo] com o estudo de como eles são formulados e desempenhados (performed) na experiência cultural. Para uma tal integração, eu me volto aos pontos de vista desenvolvidos por Dell Hymes sobre a etnografia da comunicação" (id., p. 15). Essa perspectiva distancia Feld tanto do trabalho de Merriam (que, como já vimos, estabelecia uma separação entre o estudo do conteúdo e o da forma, seja verbal, seja do produto musical) como das propostas mais centradas no modelo da antropologia cognitiva, como Zemp. E, conforme o estudo de Rafael Bastos sobre os Kamayurá, 
Eduardo Henrik Aubert. A música do ponto de vista do nativo...

com quem partilha a referência a Hymes, trata-se de enfatizar a dimensão da comunicação, dos significados em seus contextos sociais particulares, nas performances (rituais ou não) em que eles são ativados. Diz o autor:

Os recursos comunicativos dos Kaluli são abordados, seguindo Hymes, como padrōes lógicos de material simbólico que não existem em si mesmos, mas como um meio de ativar e trazer à tona relaçôes sociais significativas por meio de expressão estruturada. Decorre dessa premissa a noção de que a explicação de uma escolha sintática, de uma alteração fonológica, de um conjunto lexical, de uma frase melódica ou de um padrão métrico não são atividades destinadas a reificar a forma lingüística ou musical, mas estão antes preocupadas em demonstrar como capacidades comunicativas estão envolvidas em uma construção cultural do padrão. (id., p. 16)

É importante marcar uma diferença fundamental com relação ao modelo analítico de Merriam. Feld, que o cita, expressa seu descontentamento com a pouca atenção dada à "teoria nativa": "Eu há muito tempo me sinto intelectualmente desconfortável com tais idéias, assumindo que, onde quer que haja música, há algum tipo de teoria subjacente a sua produção e a seu significado" (id., p. 163). Além disso, ao enfatizar o aspecto social do "pensar nativo sobre o som" (e aqui não se trata apenas de música), Feld desfaz a unilinearidade dos três níveis de análise de Merriam, mostrando que, tanto quanto os conceitos produzem música, a música também pode levar à construção do sentido e do comportamento. Afinal, como descreve pacientemente Feld, entre os Kaluli, tanto quanto a tristeza leva as mulheres a cantarem nos rituais funerários, o canto leva os homens à tristeza, e esta a um choro que também é sonorização. Os influxos e as determinações mútuas ganham espaço em relação à unilinearidade causal. 
Uma quarta pesquisa a se fazer referência é a de Ruth Stone entre os Kpelle da Libéria. Tendo defendido, em 1979, a tese de doutoramento denominada Communication and Interaction Processes in Music Events among the Kpelle of Liberia, também na Universidade de Indiana, Ruth Stone a publicou, em forma revisada, em 1982, com o nome Let the Inside Be Sweet: the Interpretation of Music Event among the Kpelle of Libéria. No livro, cujos primeiros três capítulos (de um total de seis) são destinados à discussão teórica e à contraposição de paradigmas, Stone é bastante explícita quanto a seu referencial teórico, destinado, em última instância, a superar o "paradigma dilemático" e a unificar as abordagens do estudo da música como "som" e de seu estudo como "comportamento". Ruth Stone define o "evento musical", seu quadro analítico, da seguinte forma: "aquela interação da qual os participantes derivam significado. Alcança-se o estudo da música processualmente ao se analisar os componentes de transmissão e de recepção do processo interpretativo" (Stone, 1982, p. 34).

Ruth Stone está trabalhando aqui com dois referenciais importantes: o interacionismo simbólico e a teoria da comunicação semiótico-cibernética (Stone \& Stone, 1981, pp. 215-16). Interessa-lhe mostrar que a significação se dá de forma dinâmica no decurso de eventos determinados: "O significado não é algo inerente a um objeto, evento, símbolo ou qualquer outro fenômeno; o significado é construído com base nesses fenômenos" (id., p. 216). Em uma das afirmaçôes em que condensa sua proposta teórica, Stone diz que "a construção do significado nos eventos musicais envolve um processo interpretativo por meio do qual os participantes relacionam a informação em potencial num evento musical a um mapa cognitivo dinâmico e atualizável e sua própria condição proposital" (ibid.). Aqui fica clara a distância com relação à antropologia cognitiva - ainda que a questão seja a da significação atribuída aos eventos, essa é compreendida como um processo que se desenvolve 
Eduardo Henrik Aubert. A música do ponto de visTa do nativo...

em contextos sociais sempre em transformação. Como sintetizou Kofi Anyidoho, em sua resenha ao livro, "trabalhando com base na premissa de que o significado é um produto social, Stone foca seu interesse pelo evento musical na 'interação dos participantes', um direcionamento que está afinado com sua outra premissa de que significado e significação nesses eventos não são necessariamente fixos e predeterminados, mas antes dinâmicos e emergentes" (Anyidoho, 1984, p. 355). Daí decorre a elaboração das "entrevistas retroativas" como método privilegiado de pesquisa: gravar eventos musicais e tentar, junto com os nativos, reconstruir seu significado.

Stone assume também uma posição interessante com relação ao debate êmico-ético:

Os traços salientes de uma música, tais como concebidos pela população que participa em sua criação e na apreciação de sua performance, podem ser bastante distintos daqueles identificados por uma análise em que apenas conceitos ocidentais são empregados. Em última análise, entretanto, o pesquisador ocidental não pode jamais escapar totalmente da relevância de sua formação. (Stone, 1981, p. 188)

Trata-se de combinar êmico e ético em um processo intersubjetivo que envolve o pesquisador e a população estudada. A exposição etnomusicológica envolve, assim, "uma constante e deliberada tensão entre as relevâncias do etnomusicólogo ocidental e os padrões de ideação dos participantes kpelle" (id., p. 189). Ao proceder dessa forma, Ruth Stone rompe ainda uma vez com o modelo associado à antropologia cognitiva, em que o paradigma êmico era dominante e mesmo exclusivo. Vê-se como vai se delineando, em todos esses trabalhos relacionados, um paradigma de estudo bastante distinto. 
Revista de Antropologia, São Paulo, USP, 2007, v. 50 No 1.

A quinta e última monografia a que se aludirá neste item é Why Suyá Sing: a Musical Anthropology of an Amazonian People, de Anthony Seeger, publicada em 1987. Aqui, trata-se de um trabalho declaradamente bastante propositivo, cujo prefácio pretende estabelecer a diferença entre a perspectiva de Merriam, defensor de uma "antropologia da música" em sua obra homônima de 1964, e a do próprio Seeger, que pretende realizar uma "antropologia musical". Diz o autor:

Uma antropologia da música olha para a forma como a música é parte da cultura e da vida social. Diferentemente, uma antropologia musical olha para a forma como performances musicais criam diversos aspectos da cultura e da vida social. Em vez de estudar a música na cultura, uma antropologia musical estuda a vida social como performance. Em vez de assumir que existe uma matriz social e cultural preexistente e logicamente anterior, dentro da qual a música é realizada, ela examina a forma como a música é parte da própria construção e interpretação das relações e dos processos sociais e conceituais. Por meio de sua ênfase na performance e na mise-enscène de processos sociais mais do que em leis sociais, essa antropologia musical compartilha uma ênfase no processo e na performatividade comum a muito da antropologia contemporânea. (Seeger, 1987b, p. xiv)

A análise de Seeger está baseada na chamada Cerimônia do Rato, que acontece entre os Suyá quando da integração de um bebê à sociedade suyá, que passa a ser reconhecido como uma criança que tem um nome - é um rito de passagem. Trata-se, mais particularmente, de uma cerimônia particular, realizada entre janeiro e fevereiro de 1972. Após uma descrição dos primeiros dias da cerimônia (descrição que se completará ao final do livro), Seeger se debruça longamente sobre os gêneros vocais suyá, do ponto de vista dos conceitos nativos, sobre como os 
Eduardo Henrik Aubert. A música do ponto de vista do nativo...

Suyá pensam a origem de suas músicas, sobre o sentido da performance, do ponto de vista da criação da vida social, e sobre um caso extremamente interessante de alteração da altura absoluta no decorrer dos cantos das peças - uma análise que coloca em questão as relações entre as categorias dos nativos (que não se expressavam a respeito desse assunto) e as do pesquisador, que constatou o fenômeno consistente e repetidamente. Em uma conclusão que formaliza as dimensões teóricas do trabalho, Seeger deixa clara a importância do estudo do "pensar nativo sobre a música”, que, segundo ele, deve ser integrado como uma dimensão do processo de estruturação social, parte ativa desse processo tanto quanto reflexo dele. Ao falar disso, cita explicitamente teóricos sociais como Bourdieu, Giddens e Ortner, isto é, autores relacionados ao chamado construcionismo social, que buscam entender uma sociedade não como uma estrutura pronta, mas em seu processo de "estruturação", na terminologia de Giddens.

Ora, essas cinco monografias de que tratamos preocupam-se de forma muito intensa com as questôes relativas àquilo que significa a música para o nativo, mas o fazem de maneira substancialmente diferente dos estudos que dominaram o primeiro florescimento desse campo, associados a modelos derivados da lingüística formalista. De certa maneira, podemos dizer que estamos diante de um novo paradigma para o estudo da música do ponto de vista nativo. Para defini-lo, há pelo menos quatro pontos principais a se considerar.

Em primeiro lugar, todos esses estudos se voltam para contextos comunicativo-expressivos e buscam entender as concepções nativas como parte desses processos de comunicação. De formas distintas, as cinco obras aqui referidas se ocupam de ancorar socialmente a significação da música, atrelá-la a contextos freqüentemente de performance: pensar sobre a música é parte da performance, não algo que está subjacente a 
Revista de Antropologia, São Paulo, USP, 2007, v. 50 No 1.

ela, antecedendo-a, ou que se volta reflexivamente a ela, a posteriori. Em segundo lugar, todos esses trabalhos estão associados a um desprestígio da antropologia cognitiva, acentuado de Keil até Seeger, e a uma crítica à preeminência concedida à verbalidade, como forma de captar significados fixos em um código tido por abstrato e imóvel, a língua os trabalhos enfatizam a mobilidade dos significados no tempo, no espaço e nos grupos sociais. Em terceiro lugar, esses estudos apontam na direção de um repensar da própria noção de "teoria" como um elemento ideacional puro, pertencente ao domínio exclusivamente reflexivo. Especialmente nos trabalhos de Feld e de Seeger, a questão dos estados emocionais e dos afetos é fundamental - a tristeza no primeiro, a euforia no segundo. Em quarto lugar, enfim, trata-se de um paradigma que não se quer mais unicamente "êmico", mas que procura combinar as perspectivas "êmica" e "ética" num diálogo entre pesquisador e populações estudadas. Isso está muito claro, por exemplo, nas entrevistas retroativas conduzidas por Stone, no pós-escrito de Feld sobre a recepção de sua obra entre os Kaluli e na percepção de Seeger, que vê na troca entre nativos e pesquisador um dos elementos fundamentais da antropologia musical. Esse novo paradigma (apesar das diversidades internas) incorporou grandemente a "estrutura" musical no inventário de questôes dos etnomusicólogos, mas sempre em uma perspectiva prioritariamente antropológica, que se pode seguir em negações dialéticas, a partir da obra de Merriam, como desdobramentos e reformulações daquela perspectiva. Cabe constatar, contudo, que esse direcionamento, que ainda não parece ter cedido seu lugar de preeminência disciplinar a outro paradigma, não foi o único a se desenvolver no caminho das negações dialéticas que partem de Merriam e, ainda que muito aproximado daquele que vamos discutir a seguir, não se identifica a ele. 
Eduardo Henrik Aubert. A música do ponto de vista do nativo...

\section{E... Como eles pensam musicalmente?}

Bruno Nettl publicou em 1989 um livro sobre o pensamento musical dos Blackfoot (Nettl, 1989). O objetivo da obra era dúplice: "descrever um aspecto da cultura musical dos índios Blackfoot, as idéias e os conceitos que definem e rodeiam a música. O outro, igualmente importante, é desenvolver um exercício em método e técnica de etnografia musical, particularmente em descobrir e comunicar maneiras de se estudar e apresentar de forma compreensiva a cultura musical de uma sociedade" (id., p. ix). O livro está dividido em cinco capítulos que investigam áreas diversas do pensamento blackfoot sobre a música, especialmente "conceitos" em sentido amplo, na linhagem de Merriam (capítulo 2), e mitos sobre a origem da música (capítulo 3). Apesar de não investigar amplamente o problema da expressão (ou não) de questôes técnicas, o livro contribui com uma redefinição do procedimento taxonômico em sentido êmico, pois, de acordo com Nettl, os Blackfoot não classificam as coisas de forma hierárquica. A conclusão do livro traz à tona a questão da teoria musical nativa, perguntando-se se, apesar de "não terem meios para discutir a música em termos orais ou escritos", os Blackfoot têm ou não uma teoria da música. Nettl conclui que sim e "compila" essa teoria baseado nas recorrências em suas notas de campo, organizando-as em catorze afirmaçôes sobre a música entre os Blackfoot.

A rigor, poder-se-ia analisar esse trabalho de forma negativa, julgando pelas questôes despertadas pelas monografias analisadas no item anterior. É relevante, entretanto, não subestimar a importância do trabalho de Nettl, que parece apontar para preocupações distintas das do grupo de autores examinados no item anterior. É o que fica evidente em um artigo publicado em 1994 (id., 1994). Neste texto, Nettl identifica uma distinção entre dois objetos etnomusicológicos que, mesmo que imbricados, apontam para questôes muito particulares. Segundo Nettl, 
Revista de Antropologia, São Paulo, USP, 2007, v. 50 No 1.

\begin{abstract}
a história da etnomusicologia passou de um interesse do pensamento musical em descobrir como diferentes sociedades, por assim dizer, "pensam" música a um interesse nas idéias sobre música. De fato, na primeira parte do século XX, era senso comum entre os etnomusicólogos que, enquanto membros de todas as sociedades, incluindo as culturas tribais, pensavam musicalmente porque eles claramente compunham, desempenhavam e transmitiam entidades musicais, apenas aquelas sociedades que haviam desenvolvido sistemas de música "artística" ou "clássica" - as culturas elevadas da Europa e da Ásia - pensavam e teorizavam sobre a música e tinham idéias sobre ela. (id., p. 139)
\end{abstract}

Esse interesse, além de se expressar cronologicamente na evolução da disciplina, também refletiria, segundo Nettl, a dualidade de abordagens do "paradigma dilemático": "Existe uma tensão entre essas abordagens - elas são parte de uma cronologia, mas elas também representam, respectivamente, os pontos de vista paradigmáticos dos componentes 'musical' e 'antropológico' da etnomusicologia" (id., p. 140).

Ao longo do artigo, Nettl trabalha com informação coletada em seus mais de quarenta anos de pesquisa de campo, discutindo os Blackfoot, a música clássica do Irã, a música ocidental, entre outros domínios, apontando sempre para a imbricação entre o pensamento musical, uma forma cognitiva específica, e o pensamento sobre música. Apesar disso, na conclusão do artigo, Nettl acaba por subordinar o pensamento musical ao pensamento sobre música:

Minha abordagem do conceito de pensamento musical foi a de olhar para a relação entre idéias sobre música e idéias musicais. Eu não consegui identificar o pensamento explicitamente musical como diferente de outros tipos de pensamento e provavelmente eu não seria competente para fazê-lo. Mas eu sugiro que a forma em que os músicos pensam musicalmente, as 
Eduardo Henrik Aubert. A música do ponto de vista do nativo...

formas em que eles, por assim dizer, "pensam" sua música, depende em grande medida das formas como eles pensam seu mundo em geral. E, nesse contexto, as formas como uma sociedade pensa sobre o conceito de música, sobre a música na cultura, sobre os músicos, podem determinar muito sobre a forma como os músicos daquela sociedade pensam sua música. (id., p. 147)

Apesar da dominância do modelo do "pensamento sobre música", Nettl identifica em John Blacking uma preocupação com as questóes relativas ao pensamento musical (Nettl, 1994, p. 139). De fato, já em sua obra A Commonsense View of All Music, Blacking dedicara três capítulos a tratar das "idéias musicais, como distintas das idéias sobre a música" (Blacking, 1987, p. 51). Nos ensaios reunidos em Music, Culture and Experience, Blacking dedica-se explicitamente à questão do pensamento musical como uma forma cognitiva específica:

[...] há boas razōes para se buscar e identificar um conjunto inato, específico à espécie, de capacidades cognitivas e sensórias que os seres humanos estão predispostos a utilizar para a comunicação "musical". Ao postular um modo "musical" de pensamento e ação pré-lingüístico, não verbal, eu não estou argumentando que todas as músicas derivam dele, ou que ele está limitado à produção de música: ele também pode se manifestar em outras atividades humanas, e mesmo na organização de idéias verbais.

(Blacking, 1995b, p. 236)

Blacking está argumentando em prol da atenção simultânea ao verbal e ao não verbal no estudo das músicas não ocidentais (e ocidentais também). Nesse sentido, a preocupação com a música do ponto de vista nativo ganha uma conotação adicional, que vai além do paradigma de verbalidade que dominou a antropologia (e a etnomusicologia) por 
muito tempo e determinou a forma como as "teorias musicais nativas" foram tratadas. O que está em questão aqui é recolocar o problema do "pensamento" nos quadros de uma discussão geral sobre os padróes cognitivos humanos.

Trata-se de questão ainda muito pouco explorada, mesmo que aludida nos trabalhos de Feld e Seeger via noções como "sentimentos" e "euforia", que, de alguma forma, procuravam apreender uma especificidade cognitiva das culturas estudadas - buscando na emoção uma saída para a dominância da razão como modalidade cognitiva e expressiva -, ou mesmo explicitamente indicada por Bastos (Bastos, 1978, p. 43). A perspectiva de Blacking é, no entanto, mais ambiciosa e parece propor uma quebra paradigmática fundamental. Ela propóe que, para além da diversidade de manifestações do pensamento sobre a música em cada cultura, atrelado a contextos sociais particulares, existe uma base cognitiva universal que aproxima as sociedades ocidentais das não ocidentais e representa mesmo um dado comum da espécie, base cognitiva que não deve ser simplesmente indicada, mas que deve se tornar objeto central do interesse etnomusicológico. Seria, assim, a teoria musical uma pequena marca de diferença em face de uma base cognitiva muito mais profunda e significativa, compartilhada que é por toda a espécie? A pergunta foi formulada e talvez seja pelas respostas sugeridas que se poderá caracterizar o esforço futuro da etnomusicologia para refletir sobre o "pensamento sobre a música" e possivelmente superar, ou, ao menos, circunscrever de maneira mais adequada tal categoria. 
Eduardo Henrik Aubert. A música do ponto de visTa do nativo...

\section{Notas}

1 Mestre em História Social pela Faculdade de Filosofia, Letras e Ciências Humanas da Universidade de São Paulo (FFLCH-USP). Bolsista da CAPES.

2 A definição de Adler é a seguinte: "Uma subárea nova e importantíssima dessa parte sistemática é a 'musicologia', ou seja, a musicologia comparada, cuja tarefa é comparar a produção tonal, em especial os cantos folclóricos dos diferentes povos, países e territórios, com um objetivo etnográfico, e classificá-la, em toda a sua diversidade, segundo suas características" (Adler, 1885, p. 14). (Salvo indicação em contrário, todas as traduçōes de citaçōes em língua estrangeira são de nossa autoria.)

3 A sugestão da correlação entre instrumentos musicais e teoria musical pode ser vista em germe já em Hermann von Helmholtz, que, em 1877, tratando da influência dos diferentes instrumentos sonoros nas escalas e nos modos, reconheceu a mutabilidade desses elementos inclusive entre os "povos não cultivados ou selvagens", dentro, evidentemente, de um quadro evolucionista (Helmholtz, 1954, p. 358). Contudo, o próprio fato de que, diante dessas indicaçôes, a musicologia comparada não tenha desenvolvido um interesse pelo estudo da teoria musical não ocidental indica mais uma vez que se está diante de todo um sistema de pressupostos disciplinares extremamente fortes. (Agradecemos ao parecerista anônimo da Revista de Antropologia a indicação do texto de Helmholtz.)

4 Trata-se, originalmente, da tese de doutorado defendida na Sorbonne em 1968 (Rycroft, 1974, p. 509).

5 As resenhas de Gourlay e de John Blacking são profundamente críticas ao livro de Keil (Gourlay, 1980 e Blacking, 1981). 
Revista de Antropologia, São Paulo, USP, 2007, v. 50 oo 1.

\section{Bibliografia}

ADLER, G.

1885 "Umfgang, Methode und Ziel der Musikwissenschaft", Vierteljahresschrift für Musikwissenschaft, 1, pp. 5-20.

AMES, D. W. \& KING, A. V.

1971 Glossary of Hausa Music and Its Social Contexts, Evanston, Northwestern University Press.

ANYIDOHO, K.

1984 Resenha de Ruth Stone, "Let the Inside Be Sweet", The Journal of American Folklore, 97, 385, pp. 355-7.

BASTOS, R. J. M.

1978 A musicológica kamayurá: para uma antropologia da comunicaçāo no Alto-Xingu, Brasília, Funai.

1995 "Esboço de uma teoria da música: para além de uma antropologia sem música e de uma musicologia sem homem”, Anuário Antropológico, 93, pp. 9-73.

BLACKING, J.

1981 Resenha de Charles Keil, "Tiv Song”, American Ethnologist, 8, 4, pp. 831-3.

1987 "A Commonsense View of All Music': Reflections”, in Percy Grainger's Contribution to Ethnomusicology and Music Education, Cambridge, Cambridge University Press.

1995a Venda Children's Songs: a Study in Ethnomusicological Analysis, Chicago/Londres, University of Chicago Press.

1995b "Music, Culture, and Experience", in: Music, Culture, and Experience: Selected Papers of John Blacking, Chicago/Londres, The University of Chicago Press, pp. 223-42.

BLACKING, J. \& HOWARD, K.

1991 "John Blacking: an Interview Conducted and Edited by Keith Howard", Ethnomusicology, 35, 1, pp. 55-76. 
Eduardo Henrik Aubert. A música do ponto de vista do nativo...

BLUM, S.

1991 "European Musical Terminology and the Music of Africa", in NETTL, B. \& BOHLMAN, P. V. (eds.), Comparative Musicology and Anthropology of Music: Essays on the History of Ethnomusicology, Chicago/Londres, University of Chicago Press, pp. 1-36.

BOAS, F.

1939 The Mind of Primitive Man, Nova York, Macmillan.

1951 Primitive Art, Nova York, Capitol.

BOYER, P.

1992 "Anthropologie Cognitive", in BONTE, P. \& IZAR, M. (eds.), Dictionnaire de l'ethnologie et de l'anthropologie, Paris, PUF, pp. 158-60.

\section{CHRISTENSEN, D.}

1991 "Erich von Hornbostel, Carl Stumpf, and the Institutionalization of Comparative Musicology”, in NETTL, Bruno \& BOHLMAN, P. V. (eds.), Comparative Musicology and Anthropology of Music: Essays on the History of Ethnomusicology, Chicago/Londres, University of Chicago Press, pp. 201-9.

DJEDJE, J. C.

1983 Resenha de Ruth Stone, "Let the Inside Be Sweet, Ethnomusicology, pp. 544-6.

FELD, S.

1990 Sound and Sentiment: Birds, Weeping, Poetics, and Song in Kaluli Expression, Filadélfia, University of Pennsylvania Press.

GOURLAY, K. A.

1980 Resenha de Charles Keil, “Tiv Song”, Ethnomusicology, 4, 1, pp. 119-23.

HEADLAND, T., PIKE, K. \& HARRIS, M.

1990 Emics and Etics. The Insider/Outsider debate, Londres, Sage.

HELMHOLTZ, $\mathrm{H}$.

1954 On the Sensations of Tone as a Physical Basis for the Theory of Music, Nova York, Dover. 
Revista de Antropologia, São Paulo, USP, 2007, v. 50 no 1.

HERZOG, G.

1945 "Drum-Signalling in a West African Tribe", Word, 1, pp. 217-238.

HYMES, D.

1974 "Toward Ethnographies of Communication", in Foundations in Sociolinguistics: an Ethnographic Approach, Londres, Tavistock, pp. 1-35.

HORNBOSTEL, E. M. VON

1909 "Wanyamwezi-Gesänge", Anthropos, 4, pp. 781-800.

1928 "African Negro Music", Africa, 1, 1, pp. 30-62.

HORNBOSTEL, E. M. VON \& SACHS, C.

1914 "Systematik der Musikinstrumente. Ein Versuch", Zeitschrift für Ethnologie, 46, pp. $553-90$.

KEIL, C.

1979 Tiv Song, Chicago/Londres, The University of Chicago Press.

KUBIK, G.

1994

"Composition Techniques in Kiganda Xylophone Music. With an Introduction into Some Kiganda Musical Concepts", in KUBIK, G., Theory of African Music, Berlim, F. Noetzel, v. 1.

JONES

1973

"Resenha", in AMES, David W. \& KING, Anthony V., Glossary of Hausa Music, Bulletin of the School of Oriental and African Studies, University of London, 36, 1, pp. 192-3.

LOEB, L. D.

1984 Resenha de Ruth Stone, "Let the Inside Be Sweet", American Ethnologist, 11, 2, p. 395.

MAUSS, M.

1926 Manuel d'ethnographie (consultado em versão eletrônica no endereço http:// www.uqac.uquebec.ca/zone30/Classiques des sciences sociales/classiques/ mauss marcel/manuel ethnographie/manuel ethnographie.pdf, em 29/6/ 2007). 
Eduardo Henrik Aubert. A música do ponto de vista do nativo...

MERRIAM, A. P.

1960 "Ethnomusicology: Discussion and Definition of the Field", Ethnomusicology, 4, 3, pp. 107-14.

1967 Ethnomusicology of the Flathead Indians, Chicago, Aldine.

1980 The Anthropology of Music, Evanston, Nortwestern University Press.

NETTL, B.

1956 Music in Primitive Culture, Cambridge, Harvard University Press.

1983 The Study of Ethnomusicology: Twenty-Nine Issues and Concepts, Urbana/Chicago/Londres, University of Illinois Press.

1989 Blackfoot Musical Thought: Comparative Perspectives, Kent, Kent State University Press.

1994 "'Musical Thinking' and 'Thinking about Music' in Ethnomusicology: an Essay of Personal Interpretation", The Journal of Aesthetics and Art Criticism, 52, 1, pp. 139-48.

POWERS, W. K.

1970 "Review Essay of A. P. Merriam, Ethnomusicology of the Flathead Indians", Ethnomusicology, 14, 1, pp. 67-76.

RIEMANN, $\mathrm{H}$.

1974 History of Music Theory, Nova York, Da Capo.

RYCROFT, D.

1974 Resenha de Hugo Zemp, "Musique Dan", Bulletin of the School of Oriental and African Studies, 37, 2, pp. 509-11.

SACHS, C.

$1937 \quad$ World History of Dance, Nova York, Norton.

SEEGER, A.

1987a “Do We Need to Remodel Ethnomusicology?", Ethnomusicology, 31, 3, pp. 491-5.

1987b Why Suyá Sing: a Musical Anthropology of an Amazonian People, Cambridge et alii, Cambridge University Press. 
Revista de Antropologia, São Paulo, USP, 2007, v. 50 No 1.

STONE, R. M.

1981 "Toward a Kpelle Conceptualization of Music Performance", The Journal of American Folklore, 94, 372, pp. 188-206.

1982 Let the Inside Be Sweet: the Interpretation of Music Event among the Kpelle of Liberia, Bloomington, Indiana University Press.

STONE, R. M. \& STONE, V. L.

1981 "Event, Feedback, and Analysis: Research Media in the Study of Music Events", Ethnomusicology, pp. 215-25.

TYLER, S. A.

1969 "Introduction", in TYLER, S. A. (ed.), Cognitive Anthropology, Nova York et alii, Holt, Rinehart and Winston, pp. 1-23.

ZEMP, $\mathrm{H}$

$1971 \quad$ Musique Dan: la musique dans la pensée et la vie sociale d'une société africaine, Paris/Mouton/La Haye, Cahiers de L'Homme.

1978 "'Are'Are Classification of Musical Types and Instruments", Ethnomusicology, 22, 1, pp. 37-67.

1979

"Aspects of 'Are'Are Musical Theory", Ethnomusicology, 23, 1, pp. 5-48. 
Eduardo Henrik Aubert. A música do ponto de vista do nativo...

ABSTRACT: This article seeks to characterize the different outlooks which comparative musicology, in the first half of the $20^{\text {th }}$ century, and ethnomusicology, its heir in the second half of the century, have evolved concerning the thinking about music in the cultures they have studied. If the perception of the (non-)existence of this thinking was initially marked by the opposition to Western music theory, an acknowledgement of the diversity of its content and, thereafter, of its form, was gradually to dominate this field of study. So much so, in fact, that one might today dialectically inquire whether, over and above the diversity in the thinking about music, there would be some sort of unity in musical thinking as a cognitive modality typical of the human species.

KEY-WORDS: comparative musicology, ethnomusicology, music theory, thinking about music, musical thought.

Recebido em julho de 2007, aceito em outubro de 2007. 